\title{
Effect of Hydrotropes on Solubility and Mass Transfer \\ Coefficient of Methyl Benzoate
}

\author{
Senthil Nathan, M., Jayakumar, C. \& Nagendra Gandhi, N \\ Department of Chemical Engineering, A.C. College of Technology \\ Anna University, Chennai 600025, India \\ Tel: 91-44-2220-3515 E-mail: n_nagendra2002@yahoo.com
}

\begin{abstract}
A comprehensive investigation on the solubility and mass transfer coefficient enhancement of methyl benzoate through hydrotropy has been undertaken. The solubility and mass transfer coefficient studies were carried out using hydrotropes such as citric acid, urea and nicotinamide under a wide range of hydrotrope concentrations ( 0 to $3.0 \mathrm{~mol} / \mathrm{L}$ ) and different system temperatures ( 303 to $333 \mathrm{~K}$ ). The effectiveness of hydrotropes was measured in terms of Setschnew constant $\mathrm{K}_{\mathrm{s}}$ and reported for all hydrotropes used in this study.
\end{abstract}

Keywords: Hydrotropy, Solubilization, Mass transfer co-efficient, Separation

\section{Introduction}

Hydrotropy is a unique and unprecedented solubilization technique in which certain chemical compounds termed as hydrotropes can be used to effect a several fold increase in the solubility of sparingly soluble solutes under normal conditions. This increase in solubility in water is probably due to the formation of organized assemblies of hydrotrope molecules at critical concentrations.

Hydrotropes in general are water-soluble and surface-active compounds which can significantly enhance the solubility of organic solutes such as esters, acids, alcohols, aldehydes, ketones, hydrocarbons, and fats.

The solubility enhancement in the organic compounds could be due to the formation of molecular structures in the form of complexes. Previous experimental findings have concluded that hydrotropy is a process which goes beyond conventional solubilization methods such as miscibility, co-solvency, salting-in effect since the solubilization effected by hydrotropy was higher and more selective compared to other solubilization techniques. The effect of hydrotropes on the solubility and mass transfer coefficient for a series of organic esters such as butyl acetate, ethyl benzoate, amyl acetate, methyl salicylate and benzyl acetate was studied in our earlier publications.

It has been observed that, in many two-phase reaction systems involving a sparingly soluble organic compound like methyl benzoate, the mass-transfer coefficient was found to be very low solely due to the poor solubility of methyl salicylate in the aqueous phase. Since methyl benzoate serves as raw material/intermediate for a wide variety of chemicals and allied products and the separation of methyl benzoate from any liquid mixture seems to be difficult, this hydrotropic technique can be adapted to increase the solubility as well as to separate such mixtures effectively. Data on various aspects of hydrotropic study on the solubility and mass-transfer coefficient for methyl benzoate-water system are reported for the first time.

\section{Experimental}

All the chemicals used in this work were procured from S.D.Fine Chemicals Pvt. Ltd.,Mumbai with a manufacturer's stated purity of $99 \%$.

The experimental setup for the determination of solubility values consisted of a thermostatic bath and a separating funnel. For each solubility test, about $100 \mathrm{ml}$ of methyl benzoate previously saturated with distilled water was taken in a separating funnel and $100 \mathrm{ml}$ of a solution of the hydrotrope of known concentration was added. The separating funnel was immersed in a constant-temperature bath fitted with a temperature controller which could control the temperature within $\pm 0.1{ }^{\circ} \mathrm{C}$. The setup was kept overnight for equilibration. After equilibrium was attained, the aqueous layer was carefully separated from the ester layer and transferred into a beaker. The ester concentration was estimated by the addition of excess $\mathrm{NaOH}$ using a standardized Hcl solution with phenolphthalein as an indicator. All the solubility experiments were conducted in duplicate to check the reproducibility. The observed error in the reproducibility was $<2 \%$. 
The experimental setup for the determination of the mass-transfer coefficient consisted of a vessel provided with baffles and a turbine impeller run by a motor to agitate the mixture. The vessel used for mass transfer studies is of height $40 \mathrm{~cm}$ and of inner diameter $15 \mathrm{~cm}$. The turbine impeller diameter is $5 \mathrm{~cm}$, the width is $1 \mathrm{~cm}$ and the length is $1.2 \mathrm{~cm}$. It has four blades. The baffle is $40 \mathrm{~cm}$ high with a diameter of $1.5 \mathrm{~cm}$. There are about four baffles that rotate at a speed of $600 \mathrm{rpm}$.

For each run to measure the mass-transfer coefficient, about $250 \mathrm{ml}$ of the ester previously saturated with distilled water was added to the hydrotrope solution of known concentration. The sample was then agitated for a known time of 600 , 1200,1800 , and 2400 seconds. After the end of fixed time $t$, the entire mixture was transferred to a separating funnel. After allowing to stand for some time, the aqueous layer was carefully separated from the ester layer. The concentration of the solubilized organic ester in aqueous hydrotrope solutions at time $t$ was analyzed as done for solubility determinations. A plot of $-\log \left[1-C_{\mathrm{b}} / C^{*}\right]$ versus $t$ is drawn where $C_{\mathrm{b}}$ is the concentration of methyl benzoate at time $t$ and $C^{*}$ is the equilibrium solubility of methyl benzoate at the same hydrotrope concentration. The slope of the graph gives $k_{\mathrm{L}} a / 2.303$, from which $k_{\mathrm{L}} a$, the mass-transfer coefficient was determined. Duplicate runs were made to check the reproducibility. The observed error was $<2 \%$.

\section{Results and Discussion}

\subsection{Solubility}

The solubility of methyl benzoate standard in water is $1.43 \times 10^{-3} \mathrm{~mol} / \mathrm{L}$ at $303 \mathrm{~K}$, compared to $1.41 \times 10^{-3} \mathrm{~mol} / \mathrm{L}$ as reported by Dean (1987). Thus, the solubility values in water are in excellent agreement with the earlier reported values.

Experimental data representing the average of duplicate determinations on the effect of hydrotropes, i.e., citric acid, urea and nicotinamide on the solubility of methyl benzoate are presented in Tables 1-4 and are plotted in Figures 1-4. Citric acid is one of the hydrotropes used in this study. The solubility of methyl benzoate in water at $303 \mathrm{~K}$ in the absence of any hydrotrope is $1.43 \times 10^{-3} \mathrm{~mol} / \mathrm{L}$ (Table 1). It has been observed that the solubility of methyl benzoate in water increases significantly only after the addition of $0.40 \mathrm{~mol} / \mathrm{L}$ of citric acid in the aqueous phase. This concentration in referred to as the Minimum Hydrotrope Concentration (MHC).

Therefore, it is evident that hydrotropic solubilization is displayed only above the MHC, irrespective of system temperature. This MHC value assumes greater significance in the context of recovery of hydrotrope solutions. Since hydrotropy appears to operate only at significant concentrations of hydrotrope in water, most hydrotropic solutions release the dissolved methyl benzoate on dilution with water below MHC. The knowledge of MHC values is necessary especially at industrial levels, as it ensures ready recovery of the hydrotrope for reuse. The MHC values remained unaltered even at increased system temperatures.

The solubilization effect varies with concentration of hydrotropes (Table 1). In the present case, a clear increasing trend in the solubility of methyl benzoate was observed above the MHC of citric acid. This increasing trend is maintained only up to a certain concentration of citric acid in the aqueous phase, beyond which there is no appreciable increase in the solubility of methyl benzoate. This concentration of citric acid (hydrotrope) in the aqueous phase is referred to as the maximum hydrotrope concentration $\left(C_{\max }\right)$. From the analysis of the experimental data, it is observed that further increase in hydrotrope concentration beyond $C_{\max }$ does not bring any appreciable increase in the solubility of methyl benzoate even up to $3.00 \mathrm{~mol} / \mathrm{L}$ of citric acid in the aqueous phase. Similar to the $\mathrm{MHC}$ values, $C_{\max }$ values of hydrotropes also remained unaltered at increased system temperatures.

The knowledge of MHC and $C_{\max }$ values of each hydrotrope with respect to a particular solute assumes greater significance in this study since it indicates the beginning and saturation of the solubilization effect of hydrotropes. The values of $\mathrm{MHC}$ and $C_{\max }$ of a hydrotrope with respect to methyl benzoate may be useful in determining the recovery of the dissolved methyl benzoate even to an extent of the calculated amount from hydrotrope solutions at any concentration between $\mathrm{MHC}$ and $C_{\max }$ by simple dilution with distilled water. This is the unique advantage of the hydrotropic solubilization technique.

From the experimental data plotted in Figure 1, it can further be observed that, in order to achieve the particular solubility of methyl benzoate, say $20 \times 10^{-3} \mathrm{~mol} / \mathrm{L}$, the citric acid concentration should be $2.00 \mathrm{~mol} / \mathrm{L}$ at $303 \mathrm{~K}, 1.60$ $\mathrm{mol} / \mathrm{L}$ at $313 \mathrm{~K}, 1.40 \mathrm{~mol} / \mathrm{L}$ at $323 \mathrm{~K}$ and $1.20 \mathrm{~mol} / \mathrm{L}$ at $333 \mathrm{~K}$ in the aqueous phase. Thus it can be seen that as the system temperature increases, the concentration of citric acid required in the aqueous phase to achieve a particular solubility of methyl benzoate decreases. A similar trend has been observed for other systems also.

It has also been observed that the solubilization effect of citric acid was not a linear function of the concentration of the citric acid. The solubilization effect of citric acid increases with increase in hydrotrope concentration and also with system temperature.

A similar trend has been observed in the solubilization effect of other hydrotropes namely urea and nicotinamide. It has also been observed that the MHC values of hydrotrope used in this work range between 0.40 and $0.60 \mathrm{~mol} / \mathrm{L}$ (Table 5), 
which seem to depend on the hydrophilicity of a hydrotrope. The $C_{\max }$ values of hydrotropes range between 2.20 and $2.40 \mathrm{~mol} / \mathrm{L}$ (Table 5) in most cases. The highest value of solubilization enhancement factors $\varphi_{\mathrm{s}}$, which is the ratio of solubility values in the presence and absence of a hydrotrope has been observed in the case of citric acid as 26.66 at a system temperature of $333 \mathrm{~K}$ (Table 6).

\subsection{Mass-Transfer Coefficient}

The mass-transfer coefficient of methyl benzoate + water system in the absence of any hydrotrope was determined to be $0.92 \times 10^{-5} \mathrm{~s}^{-1}$ at $303 \mathrm{~K}$ (Table 7). The effect of different hydrotropes on the mass-transfer coefficient of methyl benzoate at different hydrotrope concentrations is also given in the same table. It can be seen that a threshold value of $0.40 \mathrm{~mol} / \mathrm{L}$ is required to effect significant enhancement in the mass transfer coefficient of the methyl benzoate + water system, as observed in the case of solubility determinations. The mass-transfer coefficient of methyl benzoate + water system increases with an increase in citric acid concentration. The maximum enhancement factor for mass-transfer coefficient of methyl benzoate + water system in the presence of citric acid was found to be 23.83(Table 7). A similar trend in the mass-transfer coefficient enhancement ( $\varphi_{\mathrm{mtc}}$ of methyl benzoate has been observed for other hydrotropes also namely urea and nicotinamide. The highest value of $\varphi_{\mathrm{mtc}}(23.83)$ has been observed in the presence of citric acid as hydrotrope at $C_{\max }$ of $2.40 \mathrm{~mol} / \mathrm{L}$.

\subsection{Effectiveness of Hydrotropes}

The effectiveness factor of each hydrotrope with respect to methyl benzoate at different system temperatures has been determined by analyzing the experimental solubility data for each case applying the model suggested by Setschenow (1951) and later modified by Pathak and Gaikar (1992), as given by the equation

$$
\left.\log \left[S / S_{\mathrm{m}}\right]\right)=K_{\mathrm{s}}\left[C_{\mathrm{s}}-C_{\mathrm{m}}\right]
$$

where $S$ and $S_{\mathrm{m}}$ are the solubility of methyl benzoate at any hydrotrope concentration $C_{\mathrm{s}}$ and the minimum hydrotrope concentration $C_{\mathrm{m}}$ (same as $\mathrm{MHC}$ ) respectively. The Setschenow constant $K_{\mathrm{s}}$ can be considered as a measure of the effectiveness of a hydrotrope at any given conditions of hydrotrope concentration and system temperature. The Setschenow constant values of hydrotropes namely citric acid, urea and nicotinamide for methyl benzoate + water system at different system temperatures are listed in Table 8 . The highest value has been observed as 0.565 in the case of citric acid as hydrotrope at $333 \mathrm{~K}$.

\section{Conclusion}

The solubility of methyl benzoate, which is practically insoluble in water has been increased to a maximum of 26.66 times in the presence of citric acid as hydrotrope with a corresponding increase in the mass transfer coefficient. This would be useful in increasing the rate of output of the desired product made from methyl benzoate. The MHC and $C_{\max }$ values of the hydrotrope with respect to methyl benzoate can be used for the recovery of the dissolved methyl benzoate and hydrotrope solutions at any hydrotrope concentration between the $\mathrm{MHC}$ and $C_{\max }$ by simple dilution with distilled water. This will eliminate the huge cost and energy normally involved in the separation of the solubilized methyl benzoate from its solution. The unprecedented increase in the solubilizing effect of hydrotropes is attributed to the formation of organized aggregates of hydrotrope molecules at a particular concentration.

\section{References}

Agarwal, M.; Gaikar, V. G. (1992). Extractive Separation Using Hydrotropes. Sep. Technol. 2, pp.79-84.

Agrawal et al., P. (2004).Hydrotropic Solubilization of nimesulide for parenteral administration. Int. J. Pharm. 274, pp. 149-155.

Badwan et al., (1982 ). The Solubility of Benzodiazepines in Sodium Salicylate Solutions and a Proposed Mechanism for Hydrotropic Solubilization. Int. J. Pharm. 13, pp.67-74.

Balasubramanian et al., M. (1989). Aggregation Behaviour of Hydrotropic Compounds in Aqueous Solutions. J. Phys. Chem. 93, pp.3865-3870.

Chen, X.; Micheu, J. C. (2002).Hydrotropes Induced Auto Catalysis in the Biphasic Alkaline Hydrolysis of Aromatic Esters. J. Colloid Interface Sci. 249, pp.172-179.

Colonia et al., (1998).Phase Relations of oand $p$ Chlorobenzoic Acids in Hydrotrope Solutions. J. Chem. Eng. Data .43, pp.220-225.

Deepak V. Dandekar, G.K. Jayaprakasha, Bhimanagouda S. Patil. ( 2008). Hydrotropic extraction of bioactive limonin from sour orange (Citrus aurantium L.) seeds. Food Chemistry, Volume 109, Issue 3,pp. 515-520.

Friberg et al., (1996). Reversible Extraction Process of Phenyl Ethyl Alcohol, a Fragrance. Ind. Eng. Chem. Res. 35, pp.2856-2859. 
Friberg, S. E.; Brancewicz, C. (1994). O/W Microemulsions and Hydrotropes: The Coupling Action of a Hydrotrope. Langmuir. 10, pp. 2945-2949.

Gaikar, V. G.; Phatak, P. V. (1999). Selective Solubilisation of Isomers in Hydrotrope Solution o-/p-Chlorobenzoic acids and o-/p-Nitro anilines. Sep. Sci. Technol. 34, pp.439-459.

Gaikar, V. G.; Sharma M. M. (1986). Extractive Separation with Hydrotropes. Solvent Extr. Ion Exch. 4,pp. 839-846.

John, A. D. (1987) ).Lange's Handbook of Chemistry; McGraw-Hill: New York.

Laura J. Rovetto, Timothy A. Strobel, Carolyn A. Koh, E. Dendy Sloan Jr. ( 2006). Is gas hydrate formation thermodynamically promoted by hydrotrope molecules? Fluid Phase Equilibria, Volume 247, Issues 1-2,pp. 84-89.

Laxman, M.; Sharma, M. M. (1990). Reduction of Isophorone with Borohydride: Change in Regio Selectivity with Hydrotropes. Synth. Commun. 20, pp.111-117.

Mahapatra et al., (1988). New Strategies in Extractive Distillation; Use of Aqueous Solution of Hydrotropes and Organic Bases as Solvent for Organic Acids. Sep. Sci. Technol. 23, pp.429-436.

Miguel G. Neumann, Carla C. Schmitt, Katia R. Prieto, Beatriz E. Goi. ( 2007). The photophysical determination of the minimum hydrotrope concentration of aromatic hydrotropes. Journal of Colloid and Interface Science, Volume 315, Issue 2,pp. 810-813.

Nagendra Gandhi et al. (1998). Solubility and Mass Transfer Coefficient Enhancement of Ethyl Benzoate through Hydrotropy. Hungarian J. Ind. Chem. 26, pp.63-68.

Nagendra Gandhi et al., (1998). Effect of Hydrotropes on Solubility and Mass-Transfer Coefficient of Butyl Acetate. $J$. Chem. Eng. Data. 43, pp.695-699.

Nagendra Gandhi, N.; Dharmendira Kumar, M. (2000).Effect of Hydrotropes on Solubility and Mass Transfer Coefficient of Amyl Acetate. Bioprocess Eng.pp. 449/0116.

Nagendra Gandhi, N.; Dharmendira Kumar, M. (2000). Effect of Hydrotropes on Solubility and Mass Transfer Coefficient of Methyl Salicylate. J. Chem. Eng. Data 45, pp.419-423.

Nagendra Gandhi, N.; Meyyappan, N. ( 2004). Solubility and Mass Transfer Coefficient Enhancement of Benzyl Acetate in Water through Hydrotropy. J. Chem. Eng. Data. 49, pp.1290-1294.

Nagendra Gandhi, N.; Meyyappan, N. (2005).Solubility and Mass Transfer Coefficient Enhancement of Benzyl Benzoate in Water through Hydrotropy. J. Chem. Eng. Data. 50, pp.796-800.

Neuberg, C. ( 1916). Hydrotropy. Biochem. Z. 76, pp.107-108.

Perry, R. H. (1997). Perry's Chemical Engineer's Handbook, 7th ed.; McGraw-Hill: New York.

Raynaud-Lacroze, P. O.; Tavare, N. S. (1993). Separation of 2-naphthol: Hydrotropy and Precipitation. Ind. Eng. Chem. Res. 32, 685-691.

Sara Nicoli, Franca Zani, Stefania Bilzi, Ruggero Bettini, Patrizia Santi.. (2008). Association of nicotinamide with parabens: Effect on solubility, partition and transdermal permeation. European Journal of Pharmaceutics and Bio pharmaceutics, Volume 69, Issue 2, pp. 613-62.

Tooru Ooya, Kang Moo Huh, Masato Saitoh, Eiichi Tamiya, Kinam Park (2005). Self-assembly of cholesterol-hydrotropic dendrimer conjugates into micelle-like structure: Preparation and hydrotropic solubilization of paclitaxel. Science and Technology of Advanced Materials, Volume 6, Issue 5,pp. 452-456. 
Table 1. Effect of citric acid concentration (C ) on the solubility (S) of methyl benzoate in water

\begin{tabular}{|c|c|c|c|c|}
\hline \multirow[t]{2}{*}{$\mathrm{C}, \mathrm{mol} / \mathrm{L}$} & \multicolumn{4}{|c|}{$10^{3} \mathrm{~S}, \mathrm{~mol} / \mathrm{L}$} \\
\hline & $\mathrm{T}=303 \mathrm{~K}$ & $\mathrm{~T}=313 \mathrm{~K}$ & $\mathrm{~T}=323 \mathrm{~K}$ & $\mathrm{~T}=333 \mathrm{~K}$ \\
\hline 0.00 & 1.43 & 1.49 & 1.62 & 1.81 \\
\hline 0.10 & 1.44 & 1.54 & 1.67 & 1.85 \\
\hline 0.20 & 1.47 & 1.61 & 1.72 & 1.96 \\
\hline 0.30 & 1.48 & 1.68 & 1.85 & 2.01 \\
\hline $0.40(\mathrm{MHC})$ & 2.51 & 3.01 & 3.36 & 3.58 \\
\hline 0.50 & 3.20 & 3.68 & 4.31 & 4.72 \\
\hline 0.60 & 3.94 & 4.61 & 5.54 & 6.60 \\
\hline 0.70 & 4.88 & 5.69 & 7.01 & 8.55 \\
\hline 0.80 & 5.70 & 6.57 & 8.22 & 10.52 \\
\hline 0.90 & 6.59 & 8.11 & 10.00 & 12.51 \\
\hline 1.00 & 7.57 & 9.10 & 12.00 & 15.03 \\
\hline 1.10 & 8.48 & 10.90 & 14.03 & 17.11 \\
\hline 1.20 & 9.32 & 12.40 & 16.40 & 20.05 \\
\hline 1.30 & 10.85 & 14.61 & 19.10 & 22.93 \\
\hline 1.40 & 11.83 & 16.23 & 21.62 & 25.46 \\
\hline 1.50 & 13.38 & 18.21 & 24.50 & 28.91 \\
\hline 1.60 & 14.43 & 20.65 & 27.53 & 32.01 \\
\hline 1.70 & 15.62 & 22.50 & 30.21 & 35.50 \\
\hline 1.80 & 17.33 & 24.70 & 32.26 & 38.36 \\
\hline 1.90 & 18.20 & 25.92 & 34.15 & 40.56 \\
\hline 2.00 & 20.11 & 28.52 & 36.00 & 43.62 \\
\hline 2.20 & 21.92 & 30.95 & 38.97 & 46.75 \\
\hline $2.40\left(\mathrm{C}_{\max }\right)$ & 23.04 & 32.06 & 40.20 & 48.25 \\
\hline 2.60 & 23.09 & 32.32 & 40.50 & 48.28 \\
\hline 2.80 & 23.15 & 32.35 & 40.54 & 48.31 \\
\hline 3.00 & 23.15 & 32.35 & 40.65 & 48.31 \\
\hline
\end{tabular}


Table 2. Effect of urea concentration (C) on the solubility (S) of methyl benzoate in water

\begin{tabular}{|c|c|c|c|c|}
\hline \multirow{2}{*}{$\mathrm{C}, \mathrm{mol} / \mathrm{L}$} & \multicolumn{4}{|c|}{$10^{3} \mathrm{~S}, \mathrm{~mol} / \mathrm{L}$} \\
\hline & $\mathrm{T}=303 \mathrm{~K}$ & $\mathrm{~T}=313 \mathrm{~K}$ & $\mathrm{~T}=323 \mathrm{~K}$ & $\mathrm{~T}=333 \mathrm{~K}$ \\
\hline 0.00 & 1.43 & 1.49 & 1.62 & 1.81 \\
\hline 0.10 & 1.43 & 1.52 & 1.71 & 1.95 \\
\hline 0.20 & 1.44 & 1.58 & 1.76 & 1.97 \\
\hline 0.30 & 1.46 & 1.69 & 1.99 & 2.13 \\
\hline $0.40(\mathrm{MHC})$ & 2.48 & 2.77 & 3.11 & 3.42 \\
\hline 0.50 & 3.19 & 3.87 & 4.01 & 4.94 \\
\hline 0.60 & 4.06 & 4.71 & 5.38 & 6.22 \\
\hline 0.70 & 4.94 & 5.88 & 6.85 & 7.71 \\
\hline 0.80 & 5.92 & 6.72 & 8.23 & 9.50 \\
\hline 0.90 & 6.38 & 8.10 & 9.85 & 11.21 \\
\hline 1.00 & 7.67 & 9.32 & 11.60 & 13.12 \\
\hline 1.10 & 8.54 & 10.61 & 13.22 & 15.20 \\
\hline 1.20 & 9.52 & 12.28 & 14.96 & 17.20 \\
\hline 1.30 & 10.64 & 13.52 & 17.11 & 19.73 \\
\hline 1.40 & 12.03 & 15.41 & 19.02 & 22.66 \\
\hline 1.50 & 12.82 & 16.84 & 21.47 & 24.91 \\
\hline 1.60 & 14.32 & 18.41 & 23.33 & 27.78 \\
\hline 1.70 & 15.20 & 20.08 & 25.24 & 30.28 \\
\hline 1.80 & 16.86 & 21.22 & 27.73 & 33.21 \\
\hline 1.90 & 17.25 & 22.20 & 28.47 & 34.59 \\
\hline 2.00 & 19.01 & 24.25 & 31.41 & 37.41 \\
\hline 2.20 & 20.57 & 26.25 & 32.93 & 39.61 \\
\hline $2.40\left(\mathrm{C}_{\max }\right)$ & 21.72 & 27.58 & 34.29 & 41.05 \\
\hline 2.60 & 21.93 & 27.65 & 34.33 & 41.10 \\
\hline 2.80 & 21.97 & 27.65 & 34.35 & 41.10 \\
\hline 3.00 & 21.97 & 27.69 & 34.35 & 41.11 \\
\hline
\end{tabular}


Table 3. Effect of nicotinamide concentration (C) on the solubility (S) of methyl benzoate in water

\begin{tabular}{|c|c|c|c|c|}
\hline \multirow{2}{*}{$\mathrm{C}, \mathrm{mol} / \mathrm{L}$} & \multicolumn{4}{|c|}{$10^{3} \mathrm{~S}, \mathrm{~mol} / \mathrm{L}$} \\
\hline & $\mathrm{T}=303 \mathrm{~K}$ & $\mathrm{~T}=313 \mathrm{~K}$ & $\mathrm{~T}=323 \mathrm{~K}$ & $\mathrm{~T}=333 \mathrm{~K}$ \\
\hline 0.00 & 1.43 & 1.49 & 1.62 & 1.81 \\
\hline 0.10 & 1.44 & 1.53 & 1.73 & 1.96 \\
\hline 0.20 & 1.61 & 1.61 & 1.78 & 2.01 \\
\hline 0.30 & 1.76 & 1.72 & 1.82 & 2.08 \\
\hline 0.40 & 1.76 & 1.81 & 1.91 & 2.19 \\
\hline 0.50 & 1.81 & 2.06 & 2.28 & 2.34 \\
\hline 0.60 (MHC) & 2.91 & 3.38 & 3.51 & 3.82 \\
\hline 0.70 & 3.07 & 3.64 & 4.08 & 4.93 \\
\hline 0.80 & 4.25 & 4.59 & 5.11 & 6.12 \\
\hline 0.90 & 5.07 & 6.01 & 6.44 & 7.65 \\
\hline 1.00 & 6.01 & 6.86 & 7.93 & 9.18 \\
\hline 1.10 & 6.93 & 8.11 & 9.28 & 10.71 \\
\hline 1.20 & 7.78 & 9.34 & 10.76 & 12.07 \\
\hline 1.30 & 8.73 & 10.52 & 12.36 & 13.77 \\
\hline 1.40 & 9.63 & 11.98 & 13.61 & 15.63 \\
\hline 1.50 & 10.67 & 13.03 & 15.11 & 17.41 \\
\hline 1.60 & 11.64 & 14.13 & 16.41 & 19.63 \\
\hline 1.70 & 12.60 & 15.37 & 18.26 & 21.20 \\
\hline 1.80 & 13.31 & 16.45 & 19.52 & 22.63 \\
\hline 1.90 & 13.92 & 17.27 & 20.33 & 23.46 \\
\hline 2.00 & 14.62 & 18.21 & 21.59 & 24.54 \\
\hline $2.20\left(\mathrm{C}_{\max }\right)$ & 15.73 & 19.43 & 22.86 & 25.84 \\
\hline 2.40 & 16.20 & 19.48 & 22.92 & 26.25 \\
\hline 2.60 & 16.22 & 19.52 & 22.99 & 26.28 \\
\hline 2.80 & 16.22 & 19.55 & 23.02 & 26.33 \\
\hline 3.00 & 16.24 & 19.55 & 23.05 & 26.33 \\
\hline
\end{tabular}


Table 5. MHC and $\mathrm{C}_{\max }$ values of Hydrotropes

\begin{tabular}{|l|l|l|}
\hline Hydrotrope & MHC, mol/L & $\mathrm{C}_{\max }, \mathrm{mol} / \mathrm{L}$ \\
\hline Citric acid & 0.40 & 2.40 \\
\hline Urea & 0.40 & 2.40 \\
\hline Nicotinamide & 0.60 & 2.20 \\
\hline
\end{tabular}

Table 6. Maximum solubilization enhancement factor of $\left(\varphi_{\mathrm{s}}\right)$ methyl benzoate

\begin{tabular}{|l|l|l|l|l|}
\hline \multirow{2}{*}{ Hydrotrope } & \multicolumn{4}{|l|}{ Maximum enhancement factor for solubility $\left(\varphi_{\mathrm{S}}\right)$} \\
\cline { 2 - 5 } & $\mathrm{T}=303 \mathrm{~K}$ & $\mathrm{~T}=313 \mathrm{~K}$ & $\mathrm{~T}=323 \mathrm{~K}$ & $\mathrm{~T}=333 \mathrm{~K}$ \\
\hline Citric acid & 16.08 & 21.52 & 24.82 & 26.66 \\
\hline Urea & 15.19 & 18.51 & 21.17 & 22.68 \\
\hline Nicotinamide & 11.00 & 13.04 & 14.11 & 14.28 \\
\hline
\end{tabular}

Table 7. Effect of hydrotrope concentration $(\mathrm{C})$ on the mass transfer coefficient $\left(\mathrm{k}_{\mathrm{La}}\right)$ of methyl benzoate

\begin{tabular}{|c|c|c|c|}
\hline Hydrotrope & $\mathrm{C}, \mathrm{mol} / \mathrm{L}$ & $\begin{array}{l}\left(\mathrm{k}_{\mathrm{La}}\right) \\
10^{5} \mathrm{~s}^{-1}\end{array}$ & $\begin{array}{l}\text { Enhancement factor for mass } \\
\text { transfer coefficient } \\
\left(\varphi_{\mathrm{mtc}}\right)\end{array}$ \\
\hline \multirow[t]{16}{*}{ Citric acid } & 0.00 & 0.92 & - \\
\hline & 0.20 & 1.68 & 1.83 \\
\hline & $0.40(\mathrm{MHC})$ & 3.14 & 3.41 \\
\hline & 0.60 & 5.91 & 6.42 \\
\hline & 0.80 & 7.23 & 7.86 \\
\hline & 1.00 & 9.44 & 10.26 \\
\hline & 1.20 & 11.16 & 12.13 \\
\hline & 1.40 & 12.91 & 14.03 \\
\hline & 1.60 & 14.04 & 15.26 \\
\hline & 1.80 & 15.16 & 16.48 \\
\hline & 2.00 & 16.57 & 18.01 \\
\hline & 2.20 & 19.44 & 21.13 \\
\hline & $2.40\left(\mathrm{C}_{\max }\right)$ & 21.92 & 23.83 \\
\hline & 2.60 & 22.26 & 24.19 \\
\hline & 2.80 & 22.51 & 24.47 \\
\hline & 3.00 & 22.87 & 24.85 \\
\hline \multirow[t]{6}{*}{ Urea } & 0.00 & 0.92 & - \\
\hline & 0.20 & 1.50 & 1.63 \\
\hline & $0.40(\mathrm{MHC})$ & 2.71 & 2.95 \\
\hline & 0.60 & 4.81 & 5.23 \\
\hline & 0.80 & 5.98 & 6.50 \\
\hline & 1.00 & 7.84 & 8.52 \\
\hline
\end{tabular}




\begin{tabular}{|c|c|c|c|}
\hline & 1.20 & 9.38 & 10.19 \\
\hline & 1.40 & 10.94 & 11.89 \\
\hline & 1.60 & 12.04 & 13.09 \\
\hline & 1.80 & 13.16 & 14.30 \\
\hline & 2.00 & 15.28 & 16.61 \\
\hline & 2.20 & 17.06 & 18.54 \\
\hline & $2.40\left(\mathrm{C}_{\max }\right)$ & 18.62 & 20.23 \\
\hline & 2.60 & 18.87 & 20.51 \\
\hline & 2.80 & 19.01 & 20.66 \\
\hline & 3.00 & 19.32 & 21.00 \\
\hline \multirow[t]{16}{*}{ Nicotinamide } & 0.00 & 0.92 & - \\
\hline & 0.20 & 1.38 & 1.50 \\
\hline & 0.40 & 2.19 & 2.38 \\
\hline & $0.60(\mathrm{MHC})$ & 3.49 & 3.79 \\
\hline & 0.80 & 4.96 & 5.39 \\
\hline & 1.00 & 6.03 & 6.55 \\
\hline & 1.20 & 7.82 & 8.50 \\
\hline & 1.40 & 9.78 & 10.63 \\
\hline & 1.60 & 11.14 & 12.11 \\
\hline & 1.80 & 12.28 & 13.35 \\
\hline & 2.00 & 13.17 & 14.32 \\
\hline & $2.20\left(\mathrm{C}_{\max }\right)$ & 14.42 & 15.67 \\
\hline & 2.40 & 14.61 & 15.88 \\
\hline & 2.60 & 14.87 & 16.16 \\
\hline & 2.80 & 15.06 & 16.37 \\
\hline & 3.00 & 15.39 & 16.73 \\
\hline
\end{tabular}

Table 8 . Setschenow Constant $\left(\mathrm{K}_{\mathrm{S}}\right)$ of Hydrotropes with respect to methyl benzoate

\begin{tabular}{|l|l|l|l|l|}
\hline \multirow{2}{*}{ Hydrotrope } & \multicolumn{4}{l}{ Setschenow Constant $\left(\mathrm{K}_{\mathrm{S}}\right)$} \\
\cline { 2 - 5 } & $\mathrm{T}=303 \mathrm{~K}$ & $\mathrm{~T}=313 \mathrm{~K}$ & $\mathrm{~T}=323 \mathrm{~K}$ & $\mathrm{~T}=333 \mathrm{~K}$ \\
\hline Citric acid & 0.481 & 0.513 & 0.539 & 0.565 \\
\hline Urea & 0.471 & 0.499 & 0.521 & 0.539 \\
\hline Nicotinamide & 0.458 & 0.475 & 0.508 & 0.518 \\
\hline Sodium Salicylate & 0.469 & 0.485 & 0.512 & 0.527 \\
\hline
\end{tabular}




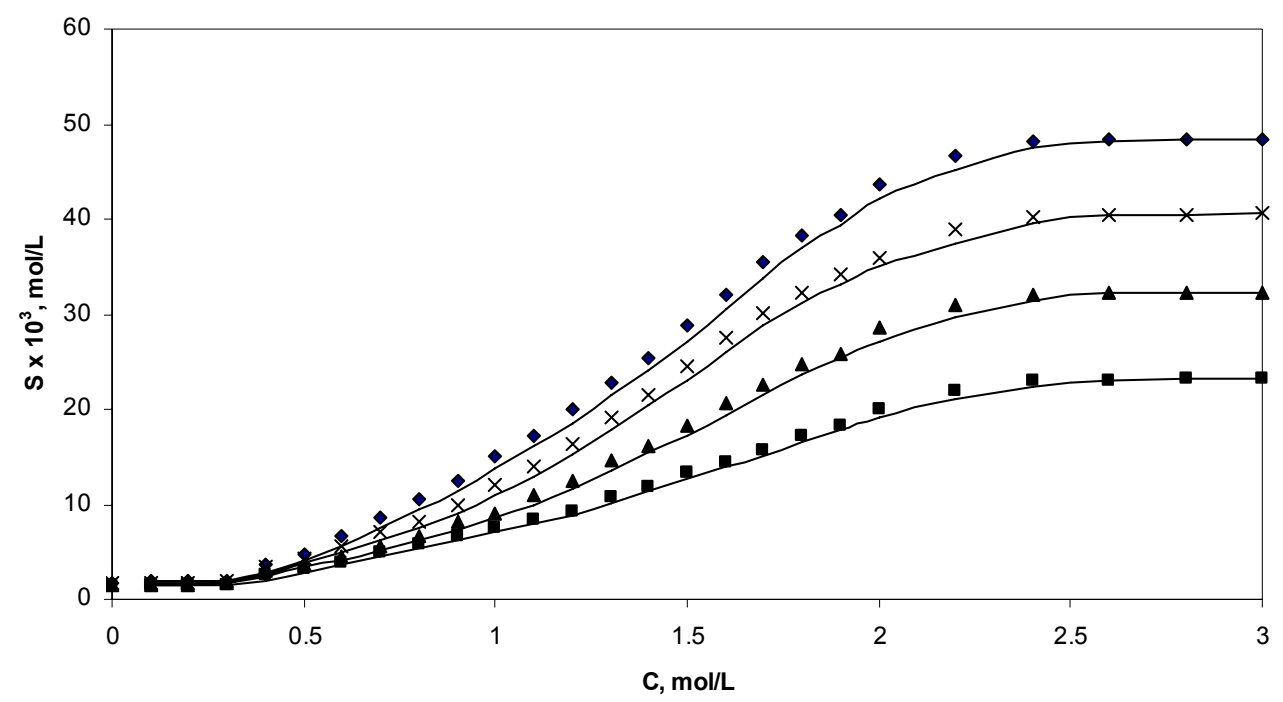

Figure 1. Effect of Citric acid concentration (C) on the solubility (S) of Methyl benzoate in water at different temperatures $\mathrm{T}=303 \mathrm{~K}(\bullet), 313 \mathrm{~K}(\mathbf{\Delta}), 323 \mathrm{~K}(\times)$ and $333 \mathrm{~K}(\mathbf{\bullet})$.

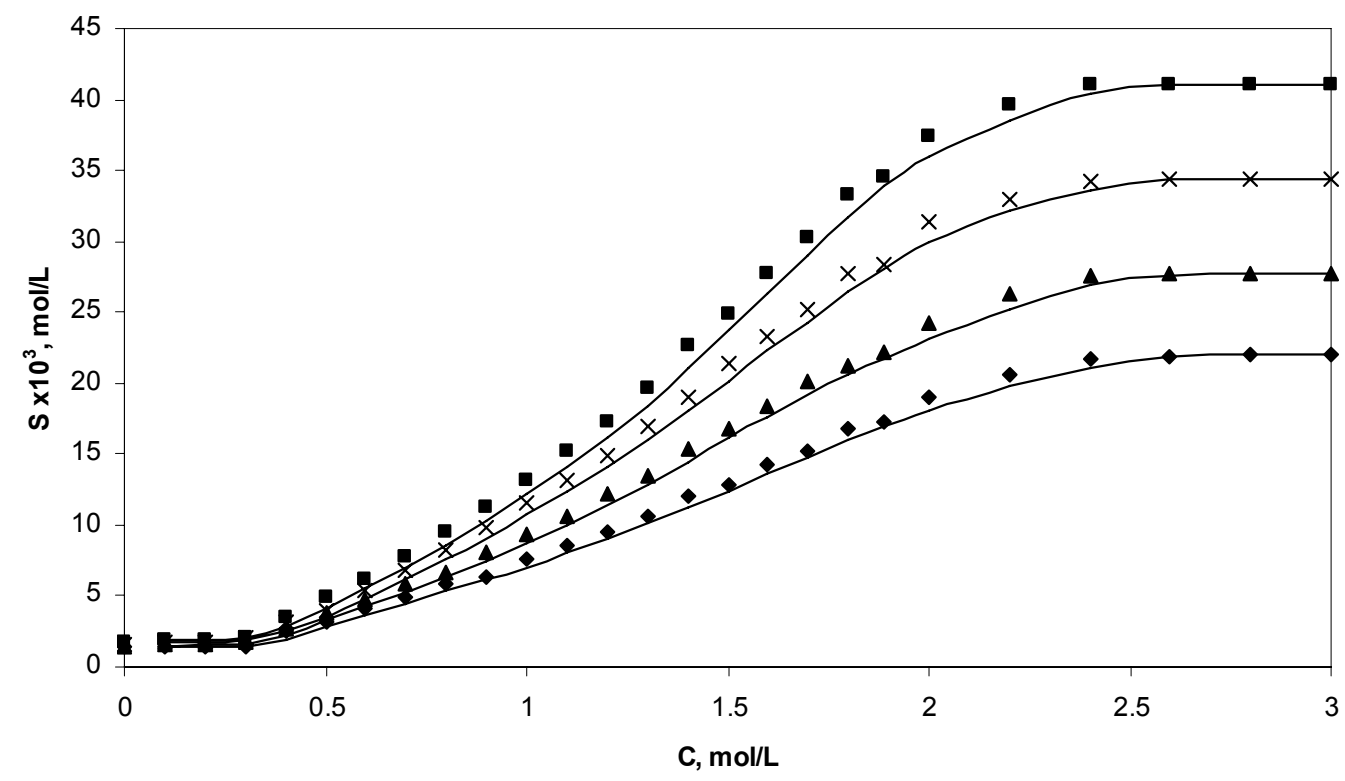

Figure 2. Effect of Urea concentration (C) on the solubility (S) of Methyl benzoate in water at different temperatures $\mathrm{T}=303 \mathrm{~K}(\bullet), 313 \mathrm{~K}(\mathbf{\Delta}), 323 \mathrm{~K}(\times)$ and $333 \mathrm{~K}(\mathbf{\bullet})$. 


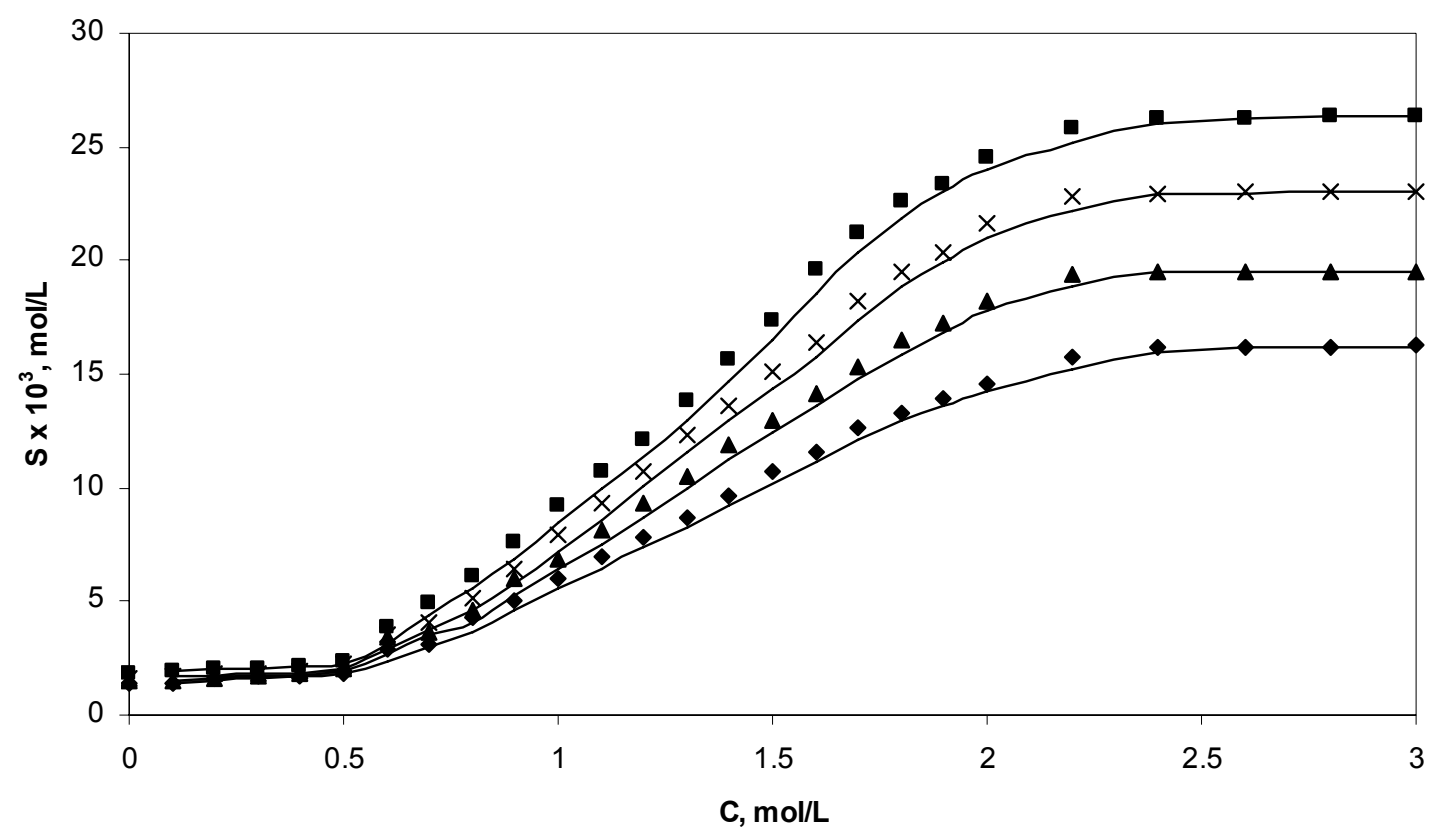

Figure 3. Effect of Nicotinamide concentration (C) on the solubility (S) of Methyl benzoate in water at different

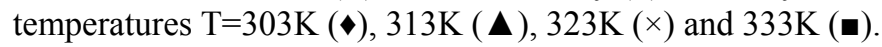

